\title{
Photosensitivity in body mass and testicular activity of brahminy myna, Sturnus pagodarum
}

\author{
Sanjay Kumar BHARDWAJ*, Praveen KUMAR \\ Department of Zoology, Chaudhary Charan Singh University, Meerut 250 004, India
}

(Received 23 December 2003; accepted 22 April 2004)

\begin{abstract}
This study analyzed photoperiodic sensitivity of brahminy myna (Sturnus pagodarum), which is a seasonally breeding bird species. During regression phase of the reproductive cycle (in early September), groups of myna were exposed to artificial photoperiods that were either close to or longer than those brahminy myna experiences at this time in wild at $29^{\circ} \mathrm{N}$. Following a 14-week exposure to such photoperiods (hours of light: hours of darkness; 13L:11D, 12L:12D, 11.5L:12.5D and 11L:13D), the birds were subjected to a longer day length (16L:8D) for another 9 weeks to test whether pre-treatment with varying photoperiods had an effect on subsequent long day photostimulation. There was a progressive increase in body mass under different pre-treatment photoperiods, with a faster increase in 11L:13D and 11.5L:12.5D than in 12L:12D and 13L:11D. When subjected to $16 \mathrm{~L}: 8 \mathrm{D}$, however, all groups showed decline in body mass. By contrast, the testes were not stimulated under 11L:13D and 11.5L:12.5D, and only one individual of the groups under 12L:12D and 13L:11D showed a small testis recrudescence. All birds except one individual of the 13L:11D group, however, showed testis recrudescence when subjected to $16 \mathrm{~L}: 8 \mathrm{D}$. These results suggest that body mass and testes have a different profile of photoperiodic response and appear to have two different threshold photoperiods for dissipating the post-reproductive refractoriness.
\end{abstract}

bird / body mass / brahminy myna / photoperiod / photorefractoriness / gonads

\section{INTRODUCTION}

Day length regulates seasonal cycles in fattening and reproduction in a number of temperate birds [1]. The breeding season ends with the development of photorefractoriness characterized by the spontaneous decline in body mass and regression of gonads, and loss of responsivity to stimulatory effects of long day lengths [2-8]. The photorefractoriness is dissipated and the responsiveness to stimulatory is recovered during progressive declining day lengths of the autumn and early winter [2, 4, 8]. Under laboratory conditions, exposure to short day lengths (e.g. 8L:16D) breaks refractoriness, and birds become responsive to long day lengths [9-12]. The rate of recovery of the sensitivity to long day photostimulation by short day lengths appears to be related to the shortness of day length and to the period of exposure to short day lengths [9-12].

The role of day length in the regulation of seasonal gonadal cycles is now also shown in a number of birds breeding at a lower latitude [7, 13-15]. However, little is

* Corresponding author: drskumar7@yahoo.com 
known about the photoperiodic mechanisms that are involved in the termination of photorefractoriness and recovery of photosensitivity in these low latitude species. Our previous studies on brahminy myna inhabiting at $29^{\circ} \mathrm{N}$ have clearly established them as a photoperiodic species $[16,17]$. In wild myna, gonadal recrudescence begins in the spring (day length $=\sim 12 \mathrm{~h}$ ) and gonads mature reproductively in May/June (day length $=\sim 14 \mathrm{~h}$ ). Then myna shows spontaneous gonadal regression in late July/August (day length $=\sim 13 \mathrm{~h}$ ) when day lengths are still longer than those that initiate recrudescence in the spring, suggesting the onset of photorefractoriness [5]. In the laboratory, an $11 \mathrm{~L}: 13 \mathrm{D}$ photoperiod is non-stimulatory, but birds show a response to $\geq 12 \mathrm{~L}: 12 \mathrm{D}$ photoperiod. Furthermore, on exposure to a longer day length, such as 15L:9D, myna undergoes a testicular growth-regression cycle in 4 months $[5,12]$. Therefore, brahminy myna presents a useful model to investigate the photoperiodic mechanisms involved in low-latitude birds since so little is known of the seasonality in these species. In the present study, we investigated the recovery of sensitivity of the photoperiodic response system of refractory brahminy myna under photoperiods that were slightly shorter and longer than the threshold photoperiods for the photostimulation of gonads in this species.

\section{MATERIALS AND METHODS}

Experiments were performed on adult male brahminy myna (Sturnus pagodarum). They were procured locally $\left(29^{\circ} 01^{\prime} \mathrm{N} ; 77^{\circ}\right.$ $45^{\prime} \mathrm{E}$ ) in August 2002, and acclimatized to captive conditions under natural day lengths (NDL) for 2 weeks before they were exposed to experimental conditions. At this latitude, the day length (sun rise to sunset) varies from $11.05 \mathrm{~h}$ in December (minimum day length) to $14.57 \mathrm{~h}$ in June (maximum day length). Food and water were freely available to all birds, and replenished twice daily during the day-time.

The experiment started in the second week of September 2002 when all birds were in the refractory phase of their annual cycle [16]. At this time, all birds had normal body mass ( 45 to $52 \mathrm{~g}$ ) and small testes (testicular volume $=\sim 0.52 \mathrm{~mm}^{3}$ ). Four groups ( $\mathrm{N}=5$ or 6 each) of myna were exposed to short day lengths (8L:16D) in order to acclimatize them to artificial laboratory conditions on a photoperiod which is otherwise non-inductive [5]. Thereafter, the birds received different photoperiods for 14 weeks as follows: 11L:13D (Group I), 11.5L:12.5D (Group II), 12L:12D (Group III) and 13L:11D (Group IV). After 14 weeks, all groups were subjected to a longer photoperiod (16L:8D) for another 9 weeks to test for the recovery of sensitivity to long day photostimulation as a result of pre-exposure to the different photoperiods. Thus, the experiments lasted for a total duration of 23 weeks.

The birds were housed in wire-mesh cages (size $45 \times 25 \times 25 \mathrm{~cm}^{3}$ ). Artificial light:dark (LD) cycles were provided by 14 watt fluorescent tubes (CFL) at an intensity of $\sim 500$ lux. Observations on body mass and testis volume were taken at the beginning and the end of the experiment, and at appropriate intervals during the experiment. Body mass was recorded on a top pan balance providing an accuracy of $0.1 \mathrm{~g}$. The size of the testis was measured as the testicular volume. For this, the dimensions of the left testis of each bird were recorded by unilateral laparotomy performed under local anesthesia, and the testis volume was calculated using the formula $4 / 3 \pi a b^{2}$, where $a$ and $b$ denote half of the long (length) and short (width) axes, respectively.

The data are presented as mean \pm SEM. They were analyzed using one-way analysis of variance with repeated measures (1-way RM ANOVA) when the response of a group was compared as a function of time, followed by the Student Newman Keuls posthoc test if ANOVA indicated a significance of difference. We used 1-way ANOVA without repeated measure in comparing the means of the different groups on selected observations. The student $t$-test (unpaired) 

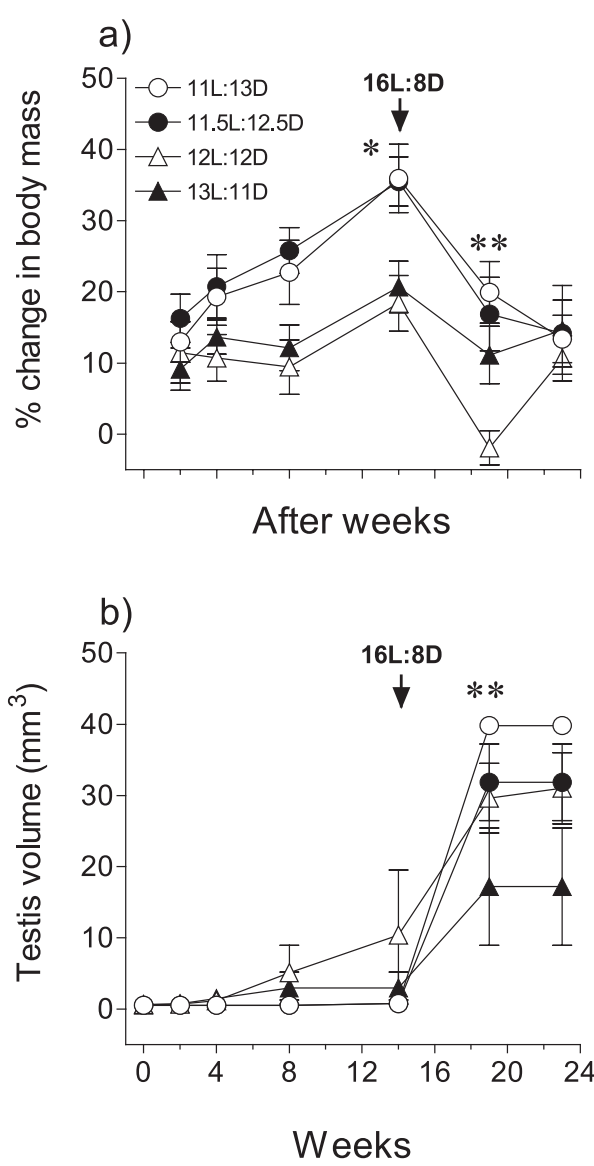

Figure 1. Shows response in body mass (a) per cent change - and testes (b) - testis volume - of photorefractory brahminy myna on exposure to 11L:13D, 11.5L:12.5D, 12L:12D and 13L:11D for 14 weeks, and subsequently to $16 \mathrm{~L}: 8 \mathrm{D}$ for 9 weeks, as indicated by an inverted arrow. Data are plotted as mean \pm SEM for 5 or 6 birds. Significance of difference $(P<0.05)$ is indicated as follows: * difference from week 0 observation in respective photoperiods and $* *$ difference from the value on week when the birds were transferred to $16 \mathrm{~L}: 8 \mathrm{D}$.

was used when two groups were compared on a day. Significance was taken at $P<0.05$.

\section{RESULTS}

The results are shown in the Figures 1a and $1 \mathrm{~b}$. Body mass progressively increased under different photoperiods (Fig. 1a) although a gain in body mass appeared to be photoperiod-dependent. For example on weeks 8 and 14 , the body mass of birds in group I (11L:13D) and group II (group 11.5L:12.5D) was significantly $(P<0.05)$ higher than those in group IV (13L:11D). On exposure to $16 \mathrm{~L}: 8 \mathrm{D}$, however, the body mass declined significantly $(P<0.05$; one way RMANOVA) in groups I, II and III (Fig.1a), but not in the group IV (Fig. 1a) although a few birds of group IV showed a decline in body mass as well.

Figure $1 \mathrm{~b}$ shows testicular response. The testes were not stimulated during 14-week exposure to all four photoperiods, except a small stimulation. When subjected to 16L:8D, however, the testes recrudesced in all individuals of all four groups although the responses were variable. For example, whereas all birds of $11 \mathrm{~L}, 11.5 \mathrm{~L}$ and $12 \mathrm{~L}$ photoperiods had fully enlarged testes, one individual of a 13L photoperiod showed a partial response and one individual did not show a photostimulation. At the end of 9 weeks of 16L:8D, the mean testis volume of birds coming from $11 \mathrm{~L}, 11.5 \mathrm{~L}$ or $12 \mathrm{~L}$ was significantly larger $(P<0.05)$ than that of the $13 \mathrm{~L}$ birds (Fig. 1b).

\section{DISCUSSION}

The present results were consistent with our earlier findings on this species [5, 17] and the finding from others on its closest relative, the European starling (Sturnus vulgaris) living at a relatively high latitude [18]. Clearly, brahminy myna undergoes spontaneous seasonal changes in its response to photoperiods, and such changes appear to be photoperiodically regulated [8]. It appears that photorefractory brahminy myna dissipate their refractoriness in response to gradual decrements in natural photoperiods at $29^{\circ} \mathrm{N}$ where day length (sun rise and sunset) ranges from a minimum $11.05 \mathrm{~h}$ in December to $14.57 \mathrm{~h}$ in June. In early September, brahminy myna were refractory and a small initiation in an individual of 
groups III and IV exposed, respectively, to 12L:12D and 13L:11D might be a reflection of individual variations within the population with regards to the photoperiodic responsiveness. Such an inter-individual difference within a group suggests that all birds of a population may recover from photorefractoriness in a larger temporal window.

An important observation of the present study is the difference in response between body mass and testes, as has been argued earlier in other species [7, 19, 20]. 11L:13D and 11.5L:12.5D induced an increase in body mass, but also induced testis recrudescence (Figs. 1a and 1b). Also, the increase in body mass was relatively small under 12L:12D and 13L:11D which induced small testis recrudescence in one or a few individuals (Figs. 1a and 1b). An increase in body mass under $11 \mathrm{~L}$ and $11.5 \mathrm{~L}$ photoperiods, which were otherwise non-inductive or weakly inductive in terms of testicular response (Figs. 1a and 1b), was consistent with the idea that birds gain in body mass prior to gonadal growth in order to support the activities associated with reproduction. It is known in a migratory species, the blackheaded bunting (Emberiza melanocephala), that the increase in body mass precedes testicular recrudescence [21]. In the wild, brahminy myna begins to recrudesce their testes in March/April when day length is $\sim 12.5 \mathrm{~h}$, and show full gonadal development in May/ June when day length is $\sim 14 \mathrm{~h}$. Myna begins to increase its body mass in January through March, when day length varies in between 11 to $12.5 \mathrm{~h}$. Changes in body mass could be independent of the reproductive response to a photoperiod in a non-migratory species. We propose to investigate this in a future study on this species.

\section{ACKNOWLEDGEMENTS}

Financial support from the Council of Scientific and Industrial Research, New Delhi through a research project (37(1074)/01-EMR-II) to SKB is acknowledged. Authors are grateful to
Professor Vinod Kumar for valuable suggestions and also thank Professor S.V.S. Rana, Head of the department for providing laboratory facilities.

\section{REFERENCES}

[1] Wingfield JC, Farner DS. Control of seasonal reproduction in temperate zone birds. Prog Reprod Biol 1980, 5: 62-101.

[2] Farner DS, Donham RS, Matt KS, Mattocks PW, Moore MC, Wingfield JC. The nature of photorefractoriness. In: Mikami S, Homma K, Wada M (Eds), Avian Endocrinology: Environmental and ecological perspectives, Japan Sci Soc Press, Tokyo, Springer-Verlag, Berlin, 1983, p 149-166.

[3] Tewary PD, Kumar V. Photoperiodic responses of a subtropical migratory finch, the blackheaded bunting, Emberiza melanocephala. Condor 1982, 84: 168-171.

[4] Nicholls TJ, Goldsmith AR, Dawson A. Photorefractoriness in birds and comparison with mammals. Physiol Rev 1988, 68: 133-176.

[5] Kumar BS, Kumar V. Seasonal reproduction in subtropical brahminy myna, Sturnus pagodarum: Role of photoperiod. Gen Comp Endocrinol 1991, 83: 354-365.

[6] Kumar V, Jain N, Singh BP, Kumar BS. Plasma levels of luteinizing hormone in intact and castrated blackheaded bunting (Emberiza melanocephala) exposed to stimulatory and non stimulatory photoperiods. Reprod Nutr Dev 1993, 33: 143-150.

[7] Kumar V. Photoperiodism in higher vertebrates: an adaptive strategy in temporal environment. Indian J Exp Biol 1997, 35: 427437.

[8] Misra M, Rani S, Singh S, Kumar V. Regulation of seasonality in the migratory male blackheaded bunting (Emberiza melanocephala). Reprod Nutr Dev 2004, 44: 341352.

[9] Turek FW. The termination of the avian photorefractory period and subsequent gonadal response. Gen Comp Endocrinol 1975, 26: $562-564$.

[10] Nicholls TJ, Storey CR. The effect of duration in the daily photoperiod on recovery of photosensitivity in photorefractory canaries (Serinus canarius). Gen Comp Endocrinol 1977, 31: 72-74. 
[11] Kumar V, Tewary PD. Circadian rhythmicity and the termination of refractory period in the blackheaded bunting (Emberiza melanocephala). Condor 1984, 86: 27-29.

[12] Kumar V, Kumar BS. Termination of photorefractoriness in the brahminy myna, Sturnus pagodarum: Role of photoperiod and gonadal hormones. Indian J Exp Biol 1992, 30: 48-53.

[13] Thapliyal JP, Gupta BBP. Reproductive cycles of Birds. In: Saidapur SK (Ed), Reproductive cycles of Indian vertebrates, Allied Publishers Ltd, New Delhi, 1989, p 273.

[14] Hau M, Wikelski M, Wingfield JC. A neotropical forest bird can measure the slight changes in tropical photoperiod. Proc R Soc Lond 1998, 265: 89-95.

[15] Hau M. Timing of breeding in variable environments: tropical birds as model systems. Horm Behav 2001, 40: 281-290.

[16] Kumar BS. Photoperiodism in brahminy myna, Sturnus pagodarum (Gmelin), Ph.D. thesis, Meerut University, Meerut, 1992.
[17] Kumar BS, Kumar V. Photoperiodic control of annual reproductive cycle in subtropical brahminy myna, Sturnus pagodarum. Gen Comp Endocrinol 1993, 89: 149-160.

[18] Dawson A, King VM, Bentley GE, Ball GF. Photoperiodic control of seasonality in birds. J Biol Rhythms 2001, 16: 133-176.

[19] Kumar V, Tewary PD, Dixit AS. Participation of circadian mechanisms in the photoperiodic responses of the blackheaded bunting (Emberiza melanocephala). Anim Reprod Sci 1985, 9: 375-382.

[20] Kumar V. Investigations of photoperiodically induced fattening in migratory blackheaded bunting (Emberiza melanocephala) (Aves). J Zool 1988, 216: 253-263.

[21] Jain N, Kumar V. Changes in food intake, body weight, gonads and plasma concentrations of thyroxine, luteinizing hormone and testosterone in captive male buntings exposed to natural day lengths at $29^{\circ} \mathrm{N}$. J Biosci 1995 , 20: 417-426. 